\title{
Drought Exacerbates Botryosphaeria Dieback Symptoms in Grapevines and Confounds Host-based Molecular Markers of Infection by Neofusicoccum parvum
}

\author{
Erin R. A. Galarneau, ${ }^{1}$ Daniel P. Lawrence, ${ }^{1}$ Renaud Travadon, ${ }^{1}$ and Kendra Baumgartner ${ }^{2, \dagger}$ \\ ${ }^{1}$ Department of Plant Pathology, University of California, Davis, CA 95616 \\ ${ }^{2}$ United States Department of Agriculture-Agricultural Research Service, Crops Pathology and Genetics Research Unit, Davis, \\ CA 95616
}

\begin{abstract}
Neofusicoccum parvum, causal fungus of the grapevine trunk disease Botryosphaeria dieback, attacks the wood of Vitis vinifera. Because lesions are internal, using putative host-based markers of infection from leaves for diagnosis is a nondestructive option. However, their specificity under drought stress is unknown. Potted 'Cabernet-Sauvignon' were inoculated with $N$. parvum in the greenhouse after wounding (IW), and with wounded and nonwounded noninoculated controls. At 2 weeks postinoculation (WPI), half of the plants were severely stressed (SS), receiving 30\% water

putative marker genes was analyzed in leaves by qPCR at the onset of drought stress, and at 8 and 12 WPI. One marker showed consistent over-expression at 8 WPI in IW plants, regardless of water treatment, suggesting specificity to infection. By $12 \mathrm{WPI}$, higher expression of seven genes in all SS plants (across inoculation treatments) revealed specificity to drought. Cross-reactivity of markers to drought, therefore, limits their utility for disease diagnosis in the field, where drought induced by climate and deficit irrigation is common.
\end{abstract} volume of the well-watered (WW) plants. Larger lesions at 12 WPI among IW-SS plants, compared with all other treatments, revealed an interactive effect of inoculation and drought on lesion length. Expression of eight
Keywords: fungi, fruit, small fruits, pathogen detection, epidemiology, climate/weather effects
Grapevine trunk diseases-including Esca and Botryosphaeria, Eutypa, and Phomopsis diebacks - are caused by taxonomically diverse fungi that induce chronic infections in the permanent, woody structure of the vine (i.e., trunk, cordon, spurs) (Bertsch et al. 2013; Gramaje et al. 2018). The infections develop within the wood without causing external symptoms for months to years (Bertsch et al. 2013). External symptoms range from the diagnostic interveinal and marginal leaf scorch/discoloration caused by Esca, to the death of fruiting positions (spurs) in the canopy, caused by all four trunk diseases.

This long delay between infection and symptom expression means that trunk diseases are not always obvious to growers until symptoms appear, which is typically when the vineyard is mature (Munkvold et al. 1994). There are preventative practices, which have been shown to be effective at minimizing infections of pruning wounds, including: (i) delaying pruning until late winter, when the risk of infection is lower (Petzoldt et al. 1981), (ii) double pruning (a nonselective trimming of canes to uniform height in early winter, followed by

${ }^{\dagger}$ Corresponding author: K. Baumgartner, Kendra.Baumgartner@usda.gov

Mention of trade names or commercial products is solely for the purpose of providing specific information and does not imply recommendation or endorsement by the USDA. USDA is an equal opportunity provider and employer.

Funding: This research was funded by grant 2012-51181-19954 to K. Baumgartner and R. Travadon from the USDA, National Institute of Food and Agriculture Specialty Crops Research Initiative.

*The $\boldsymbol{e}$-Xtra logo stands for "electronic extra" and indicates that one supplementary figure is published online.

The author(s) declare no conflict of interest.

Accepted for publication 22 February 2019.

This article is in the public domain and not copyrightable. It may be freely reprinted with customary crediting of the source. The American Phytopathological Society, 2019. hand-pruning in late winter to remove potentially infected wood after the first pass) (Weber et al. 2007), and (iii) applying pruning-wound protectants, which include fungicides, toxic barriers, or biocontrols sprayed or sometimes painted onto fresh pruning wounds (Amponsah et al. 2012; Halleen et al. 2010; Pitt et al. 2012; Rolshausen and Gubler 2005; Rolshausen et al. 2010; Sosnowski et al. 2013). These practices are optimally effective, and thus have the greatest economic benefit (Kaplan et al. 2016), if adopted when the vineyard is young, before infections are established and the resulting external symptoms appear. Nonetheless, surveys in California suggest that grape pest-control advisers (Hillis et al. 2016) and growers alike (Hillis et al. 2017) tend to adopt preventative practices in mature vineyards, after external symptoms appear. With no option for eradication of the infection, other than cutting out an infected vine canopy and retraining the vine from the base of the trunk (a practice known as 'remedial vine surgery' [Sosnowski et al. 2011a] or 'trunk renewal' [Calzarano et al. 2004]), economic losses from not adopting practices in a preventative manner are not only due to reduced yields (Kaplan et al. 2016), but also to the additional costs of replanting entire vineyards prematurely (Sipiora and Cuellar 2014).

Adoption of preventative practices in young vineyards might increase if growers had an early detection tool to confirm infection before symptoms appear. Nondestructive methods of sampling asymptomatic vines have been sought after by researchers for years. Detection of fungal metabolites has been proposed as one such method, but their levels are not always detectable (Mahoney et al. 2005 ) and the metabolites are in some cases nonspecific (Evidente et al. 2000; Tabacchi et al. 2000). Additionally, this approach relies on time-consuming and costly purification and identification by High-Performance Liquid Chromatography (HPLC). Serological assays can detect low amounts of proteins secreted by the Esca pathogens Phaeomoniella chlamydospora (Fleurat-Lessard et al. 2010) and Phaeoacremonium minimum (Fleurat-Lessard et al. 2014), and the Eutypa-dieback pathogen Eutypa lata (Octave et al. 2009), but sap exudates must be collected from the wood under humid conditions, which may not occur often in all regions.

Development of an early detection tool is also hampered by unpredictable symptom expression, which makes it difficult for researchers 
to recommend when growers might sample asymptomatic vines. When examined in asymptomatic leaves, chlorophyll fluorescence readings and other photosynthetic stress responses have been shown to be associated with later onset ( 1 week to 2 months) of the apoplectic stage of Esca (Christen et al. 2007; Letousey et al. 2010). Further, Christen et al. (2007) found that drought and Esca could be differentiated by measuring chlorophyll $a$. However, adapting this approach for routine Esca detection in the vineyard would require repeated sampling, the duration of which would be very difficult to determine, as if and when the leaf symptoms appear can be extremely variable for Esca in particular ( $\mathrm{Li}$ et al. 2017). Moreover, an early detection tool specific to Esca would have to take into account the fact that trunk pathogens cause mixed infections (Travadon et al. 2016); just because one trunk disease is absent, does not mean other pathogens are not present.

Czemmel et al. (2015) assessed a qPCR assay using host-based molecular markers of infection, which were developed from RNAseq data, and were expressed in asymptomatic leaves during the early stage of infection by the Botryosphaeria-dieback pathogen Neofusicoccum parvum (Pennycook \& Samuels) Crous, Slippers \& A.J.L. Phillips. Application of such markers to the field necessitated studies beyond the experimental design in the greenhouse of vines only with and without infection. A plant's response to vessel disruptions induced by fungal pathogens has been associated with more severe external symptoms and a loss of hydraulic function (Sun et al. 2013; Trapero et al. 2018). Furthermore, vascular pathogens can induce a high level of vessel disruption, such that symptoms mimic drought stress (Yadet and Thomma 2013). Indeed, numerous Botryosphaeriaceae species have been shown to cause more severe lesions (i.e., wood symptoms) in grapevines under drought stress (Qiu et al. 2016; van Niekerk et al. 2011). Vines infected by P. chlamydospora and E. lata had disrupted stomatal conductance, lower leaf water potential (LWP), and a higher incidence of leaf symptoms under drought stress (Edwards et al. 2007a, b; Sosnowski et al. 2011b).

It is important to ensure the specificity of host-based markers of infection to pathogen presence and not to abiotic stress. Drought stress alone, for example, can cause transcriptional changes in grapevines (Cramer et al. 2007; Haider et al. 2017a), as do other abiotic stresses (Cramer et al. 2007; Pontin et al. 2010; Vannozzi et al. 2017; Xin et al. 2013). Both drought (Haider et al. 2017a; Haider et al. 2017b) and several vascular pathogens (e.g., N. parvum [Massonnet et al. 2017], Pierce's disease bacterium Xylella fastidiosa [Lin et al. 2007], Bois noir phytoplasma [Albertazzi et al. 2009]) have been shown to induce changes in similar pathways involving primary and secondary metabolism, hormone-mediated signaling, ROS detoxification, and WRKY transcription factors. Furthermore, when biotic and abiotic stresses co-occur, a plant's response and a pathogen's ability to infect can be altered (Ramegowda and Senthil-Kumar 2015), and indeed some plant-pathogen defenserelated genes were found to be up-regulated under drought stress in the absence of a pathogen (Haider et al. 2017b). Transcriptomic analyses of the combination of drought stress and pathogen infection illustrated differences in the host response, depending on if only drought, only pathogen, or both were present (Gupta et al. 2016; Sinha et al. 2017). The objectives of the current study were (i) to determine the interactive effects of $N$. parvum and drought stress on wood lesion development, and (ii) to test previously determined putative host-based molecular markers of infection for expression in stressed and nonstressed plants, with and without infection.

\section{Materials and Methods}

Grapevine propagation and $N$. parvum inoculation. Dormant 1-year-old cuttings of Vitis vinifera L. 'Cabernet-Sauvignon' clone 29 were trimmed to a consistent length $(\sim 20 \mathrm{~cm})$ retaining one to two nodes, surface disinfested in $1 \%$ sodium hypochlorite for $15 \mathrm{~min}$, and soaked in water overnight. Cuttings were then callused in a mixture of perlite and vermiculite $(1: 1, \mathrm{vol} / \mathrm{vol})$ at $30^{\circ} \mathrm{C}$ and $100 \%$ humidity for 21 days. Once callused and producing root and shoot initials, cuttings were coated in melted Paraffin wax (Gulf Wax; Royal Oak Enterprises, Roswell, GA, U.S.A.) to prevent moisture loss, and potted in $10 \times 10$-cm pots with sterile potting mix amended with Redwood bark and slow-release fertilizer (Osmocote Pro 24-49, Scotts, Marysville, OH, U.S.A.). Potted grapevines were grown under greenhouse conditions (natural sunlight photoperiod [approximately $14 \mathrm{~h}$ per day], $25 \pm 1^{\circ} \mathrm{C}$ [day], $18 \pm 3^{\circ} \mathrm{C}$ [night]) for 3 weeks before inoculation.

A mycelial suspension of $N$. parvum isolate UCD646So was produced according to Travadon et al. (2013) with the concentration of mycelial fragments estimated with a hemacytometer, adjusted with sterile potato dextrose broth (PDB; Sigma Aldrich, St. Louis, MO, U.S.A.) to $1 \times 10^{6}$ mycelial fragments per ml. Plants were divided evenly among three inoculation treatments $(n=24$ plants per treatment): inoculated wounded (IW), noninoculated wounded (NIW), and noninoculated nonwounded (NINW). For IW and NIW plants, a power drill was used to produce a wound $(2 \mathrm{~mm}$ diameter by $3 \mathrm{~mm}$ depth), approx. $2 \mathrm{~cm}$ below the uppermost node in the lignified cane, and $20 \mu 1$ of mycelial suspension or sterile PDB, respectively, was pipetted into the wound, which was immediately sealed with Vaseline (Unilever, Rotterdam, London, UK) and Parafilm (Bemis Co., Neenah, WI, U.S.A.) to prevent inoculum desiccation. One day later, a second set of plants as a replicate experiment were inoculated using the same experimental design (three inoculation treatments, $n=24$ plants per treatment), with fresh inoculum. The two experiments were arranged in a completely randomized design on separate benches in a greenhouse at the Armstrong Experiment Station, University of California, Davis from June to September 2014.

Drought stress. Starting at 2 weeks postinoculation (WPI), drought was imposed on 12 plants in each inoculation treatment (IW, NIW, and NINW), in each experiment, to give two irrigation treatments: severely stressed (SS) and well-watered (WW) (Supplementary Fig. S1). To ease SS plants into drought, irrigation was decreased to $50 \%$ of the water used by the NINW-WW plants, and then by $10 \%$ every 3 days until all SS plants (IW-SS, NIW-SS, NINW-SS) received only $30 \%$ of the water used to irrigate NINW-WW plants. NIW-WW and IW-WW plants received $100 \%$ of the water volume used to irrigate the NINW-WW plants. Average water use was estimated weekly by flooding the NINW-WW group, weighing each pot after water runoff ceased, and reweighing $24 \mathrm{~h}$ later to estimate average daily water consumption and to calculate water deficits for the SS groups. Plants were watered daily based on this weekly adjusted estimate.

To confirm SS plants were under drought stress and to determine if infection brought about drought stress, plant water status was determined for representative plants in each inoculation $\times$ water treatment by measuring the leaf water potential (LWP) weekly, using a Scholander Pressure Chamber (Plant Moisture Stress Model 600, PMS Instrument Co., Albany, OR, U.S.A.) at 10:00 PST. One fully mature leaf (from leaf numbers 5 to 7 below the growing meristem) $(n=3$ per treatment) was covered in a hermetic plastic bag, the petiole was then severed, and each leaf was promptly placed in the Scholander Pressure Chamber with the petiole exposed. Compressed air was applied to the chamber until a single drop of plant sap was forced from the exposed petiole, thus determining the water status (i.e., LWP) of each leaf from different experimental treatments. Once SS plants were receiving $30 \%$ of the water applied to NINW-WW plants, LWP was maintained at approximately -8 bars $(-0.8 \mathrm{MPa})$ for WW plants and approximately -13 to -15 bars $(-1.3$ to -1.5 $\mathrm{MPa}$ ) for SS plants, levels which are considered for grapevines under field conditions during the growing season as "no stress" and "moderate to high stress", respectively (Smith and Prichard 2003).

Sample collection. The length of internal wood discoloration extending out from the inoculation site up and down the stem (lesion length) was used as a measure of disease severity among IW and NIW plants. Lesion length was measured at 12 WPI (10 weeks after drought stress was initiated on SS plants). Collection at 12 WPI covered the early stage of infection for $N$. parvum, as described in Czemmel et al. (2015). First, the roots, shoots, and bark were removed and discarded from the woody stems, which were then surface disinfested in $1 \%$ sodium hypochlorite for $2 \mathrm{~min}$, and rinsed with sterile, deionized water. Next, the stem was cut longitudinally through the 
inoculation site to reveal the internal lesion. Lesion length was measured with a digital caliper. Recovery of $N$. parvum was attempted from a $1-\mathrm{cm}$ wood section encompassing the inoculation site and $1-\mathrm{cm}$ wood sections encompassing 2, 4, and $6 \mathrm{~cm}$ below the inoculation site. From each of the four stem locations, five wood pieces (approximately 2 by 2 by $5 \mathrm{~mm}$ ) were surface disinfested in $0.6 \%$ sodium hypochlorite ( $\mathrm{pH}$ 7.2) for $30 \mathrm{~s}$ and rinsed twice for $30 \mathrm{~s}$ in two serial baths of sterile deionized water, then plated on potato dextrose agar (PDA; Difco Laboratories, Detroit, MI, U.S.A.) amended with tetracycline (1 mg/liter). Plates were incubated in darkness at $25^{\circ} \mathrm{C}$ for up to 7 days. Throughout the experiment, plants were examined visually for leaf symptoms (Reis et al. 2016), and plants that died were examined for infection at their time of death.

Expression of putative markers of infection. For measuring gene expression of previously defined putative host-based molecular markers of the early stage of infection (Czemmel et al. 2015; Table 1), and possible interactions with drought, the two youngest leaves (larger than $1 \mathrm{~cm}$ ) were collected at 2, 8, and 12 WPI. Samples were collected using flame-sterilized forceps and scissors, immediately frozen in liquid nitrogen, and stored at $-80^{\circ} \mathrm{C}$ for RNA extraction $[n=5$ plants from each inoculation treatment $\times$ water treatment $\times$ time point $\times$ experiment $=180$ collections total $]$. The same five plants were used in each sample collection, to be consistent with how vines might be repeatedly sampled for leaves in the field by a grower, as part of a detection tool for early infection. Total RNA was isolated with a CTAB-based extraction protocol, followed by a DNase treatment as described in Blanco-Ulate et al. (2013). RNA concentration and purity were measured using a NanoDrop 2000c Spectrophotometer (Thermo Scientific, Waltham, MA, U.S.A.) and agarose gel electrophoresis. cDNA was prepared from total RNA $(1 \mu \mathrm{g})$ using M-MLV Reverse transcription (Promega, Madison, WI, U.S.A.).

Then, quantitative PCR (qPCR) was performed on a Stratagene Mx3000P, using SYBR Ultra-Fast Brilliant III master mix (Agilent Technologies, Santa Clara, CA, U.S.A.), following the methods described in Czemmel et al. (2015). qPCR conditions were as follows: $95^{\circ} \mathrm{C}$ for $5 \mathrm{~min}, 40$ cycles of $95^{\circ} \mathrm{C}$ for $20 \mathrm{~s}, 60^{\circ} \mathrm{C}$ for $30 \mathrm{~s}, 72^{\circ} \mathrm{C}$ for $30 \mathrm{~s}$, followed by melt cycles from 55 to $95^{\circ} \mathrm{C}$. Primer efficiency was confirmed for test and reference primers as $>85 \%$, based on fourfold cDNA dilutions (three biological replicates per treatment $\times$ time point $x$ experiment with a negative water control; three technical replicates); primer specificity was confirmed based on dissociation curves. New primers were designed using NCBI Primer-BLAST on sequences derived from the $12 \times$ reference genome of $V$. vinifera (Ye et al. 2012). The $2^{-\Delta \Delta} C T$ method was used to normalize and calibrate transcript values relative to a reference transcript, the endogenous constitutive gene Ubiquitin (VIT_16s0098g01190) (Livak and Schmittgen 2001). Ubiquitin was selected as a reference transcript based on its consistently low coefficient of variation across biological replicates and treatments, and thus was used as a reference for all genes, so the scales of the linearized values were comparable (Czemmel et al. 2015).

Statistical analysis. An analysis of variance (ANOVA) was used to determine the effects of inoculation treatment (IW, NIW), water treatment (SS, WW), and their interaction on total lesion length (cm) and lesion length (percent stem length). NINW plants were not included in ANOVAs of lesion length because they had no lesions. Normality and homogeneity of variances were evaluated using normal probability plots and Levene's test, respectively. A $\log _{10}$ transformation was applied to LWD to meet parametric assumptions. ANOVA was performed using the MIXED procedure in SAS v. 9.2 (SAS Institute, Cary, NC, U.S.A.), with experimental replication, and its interactions with the main effects of inoculation treatment and water treatment, considered as random effects. For significant effects $(P<0.05)$, means were compared by Tukey's tests. An ANOVA was also used to determine the effects of water treatment (SS, WW) on LWP, using the same steps described above, but with time treated as a repeated measure because leaves from which LWP was measured were collected from the same plants 10 times throughout the experiment.

ANOVAs were used to determine the combined effects of inoculation and water treatments on gene expression. From RNA extracted from the leaves of plants in each inoculation $\times$ water treatment, foldchange differences in expression of a given gene, relative to that of Ubiquitin, were compared. Separate ANOVAs were performed for each time point $(2,8$, and 12 WPI $)$ and each locus. Normality and homogeneity of variances were evaluated using normal probability plots and Levene's test, respectively, and no transformations were necessary. ANOVAs were performed using the MIXED procedure in SAS v. 9.2 (SAS Institute, Cary, NC, U.S.A.), with experimental replication, and its interactions with treatment, considered as random effects. For significant effects $(P<0.05)$, means were compared by Dunnett's tests, with NINW-WW plants within the same time point as the control.

\section{Results}

$N$. parvum was successfully reisolated from all IW plants, regardless of water treatment, and not from NIW or NINW plants. $N$. parvum was isolated at $6 \mathrm{~cm}$ below the inoculation site from 9 of 24 IW-SS plants and from 1 of 24 IW-WW plants (Table 2). Neither leaf symptoms of Botryosphaeria dieback (leaf discoloration) nor dieback

Table 1. Primers for qPCR analysis of eight putative molecular markers in leaves during Neofusicoccum parvum infection of the woody stems

\begin{tabular}{|c|c|c|c|}
\hline V1 gene locus IDy & Gene name & Primer sequence $\left(5^{\prime}-3^{\prime}\right)^{\mathrm{z}}$ & Product size (bp) \\
\hline VIT_00s1455g00010 & expansin-like B1 (EXLB4) & $\begin{array}{l}\text { GTGATTGGAAGGCGGGGGTT/ } \\
\text { TGCAGAAGTTGGAACCACAATGG }\end{array}$ & 82 \\
\hline VIT_05s0020g00330 & galactinol synthase 2 & $\begin{array}{l}\text { GTGGAGGTTCACAGGGAAGG/ } \\
\text { CCTGGCTTGACTTCTCGTCA }\end{array}$ & 140 \\
\hline VIT_06s0004g06830 & glutamine-dependent asparagine synthase 1 & $\begin{array}{l}\text { CCTTGATCCTTCTGGCAGGG/ } \\
\text { AGGGTGCCGTTACTTCCATA }\end{array}$ & 137 \\
\hline VIT_08s0007g04240 & embryonic cell protein 63 & $\begin{array}{l}\text { CCACCGGATATGTAGCCACC/ } \\
\text { GCAATCTCCTCCTCGTCCAG }\end{array}$ & 94 \\
\hline VIT_09s0002g06790 & HSP2O-like chaperones superfamily protein & $\begin{array}{l}\text { AGGAGGAGGAAGAAGGCTCA/ } \\
\text { GGTAGGCAACAAGAGGCTCG }\end{array}$ & 83 \\
\hline VIT_11s0016g03950 & BURP domain-containing protein & $\begin{array}{l}\text { TGCTCAAGGTTAAGCCAGGG/ } \\
\text { GGTTTTGGGTCGGGCATTTC }\end{array}$ & 96 \\
\hline VIT_16s0115g00170 & unknown protein & $\begin{array}{l}\text { TCGAGTCATGACCCTAAGGC/ } \\
\text { TCCAACGAGAGGATAGGGGG }\end{array}$ & 149 \\
\hline VIT_18s0001g00140 & transcription activator-related & $\begin{array}{l}\text { ACTCACGATGCTTACGGCGG/ } \\
\text { TGCTTGGGCTGGATGTTGGG }\end{array}$ & 128 \\
\hline VIT_16s0098g01190 & Ubiquitin-1 & $\begin{array}{l}\text { GTGGTATTATTGAGCCATCCTT/ } \\
\text { AACCTCCAATCCAGTCATCTAC }\end{array}$ & 182 \\
\hline
\end{tabular}

\footnotetext{
${ }^{y}$ V1 annotations obtained from EnsemblPlants, grape genome IGGP_12x, INSDC Assembly GCA_000003745.2, June 2011.
}

${ }^{\mathrm{z}}$ Primers (forward/reverse) were generated by this study (in bold) or from Czemmel et al. 2015. 
developed during the 12-week experiment. The water treatments for WW and SS plants were associated with significantly different LWP (Fig. 1). Successful induction of drought stress in SS plants was evidenced by significantly lower LWP for SS plants, starting at 5 WPI. WW plants maintained an average LWP of $-0.8 \mathrm{MPa}$ and SS plants an average of $-1.5 \mathrm{MPa}$ over the 10 weeks of the two water treatments (from 3 to $12 \mathrm{WPI}$ ). The effects of water treatment on the SS plants, but not among WW plants, were first observed at 5 WPI, with wilting of stems and tendrils. By $12 \mathrm{WPI}$, SS plants were approximately one-third the size of WW plants $(0.5 \mathrm{~m}$ in length versus $1.5 \mathrm{~m}$ in length, respectively), based on visual observation.

ANOVA revealed a significant interactive effect of inoculation and water treatments on lesion length $(P=0.02)$, such that drought was associated with increased lesion length in IW-SS plants, but not in NIW-SS plants. IW-SS plants had significantly longer lesions than IW-WW plants (mean lesion lengths of $1.04 \mathrm{~cm}$ versus $0.76 \mathrm{~cm}$, respectively; $n=24$ plants, averaged across experiments; Table 2). In comparison, lesion lengths of NIW plants were half that of IW-WW plants $(0.43 \mathrm{~cm}$ and $0.39 \mathrm{~cm}$ for NIW-SS and NIW-WW plants, respectively; $n=24$ plants, averaged across experimental replicates) and NIW plants were not significantly different between water treatments (Table 2).

Eight putative host-based molecular markers of infection had no differences in expression between treatments at 2 WPI (ANOVA $P$ values ranging from 0.08 to 0.75 ). By 8 WPI (6 weeks after water treatments were imposed), expression levels were significantly different among treatments for all eight loci, except VIT $11 \mathrm{~s} 0016 \mathrm{~g} 03950$ (Table 3). However, there was not a pattern of

Table 2. Mean lesion lengths and pathogen recovery at 12 weeks postinoculation (WPI). The woody stems of potted Vitis vinifera 'Cabernet-Sauvignon' were inoculated with Neofusicoccum parvum after wounding (IW) or control plants were noninoculated and wounded (NIW). Lesion lengths averaged across two experiments ( $n=24$ plants) and different letters are significantly different $(P \leq 0.05$; Tukey's test). Pathogen recovery rates were measured at the inoculation site $(0 \mathrm{~cm})$, and 2,4 , and $6 \mathrm{~cm}$ below the inoculation site.

\begin{tabular}{|c|c|c|c|c|c|c|}
\hline \multicolumn{2}{|c|}{ Treatments } & \multirow{2}{*}{$\begin{array}{c}\text { Average lesion } \\
\text { length, cm } \\
\text { (95\% confidence } \\
\text { limits) }{ }^{\mathrm{z}}\end{array}$} & \multicolumn{4}{|c|}{$\begin{array}{c}\text { Recovery of } N \text {. parvum } \\
\text { (No. of plants out of } 24 \text { total) }\end{array}$} \\
\hline Inoculation & Water & & $0 \mathrm{~cm}$ & $-2 \mathrm{~cm}$ & $-4 \mathrm{~cm}$ & $-6 \mathrm{~cm}$ \\
\hline \multirow[t]{2}{*}{ IW } & WW & $0.76(0.57,0.95) b$ & 24 & 6 & 2 & 1 \\
\hline & SS & $1.04(0.85,1.24) \mathrm{a}$ & 23 & 12 & 11 & 9 \\
\hline \multirow[t]{2}{*}{ NIW } & WW & $0.39(0.20,0.58) \mathrm{c}$ & 0 & 0 & 0 & 0 \\
\hline & SS & $0.43(0.24,0.62) \mathrm{c}$ & 0 & 0 & 0 & 0 \\
\hline
\end{tabular}

${ }^{\mathrm{z}}$ Non-Inoculated Non-Wounded had no lesions and was not included in the analysis.

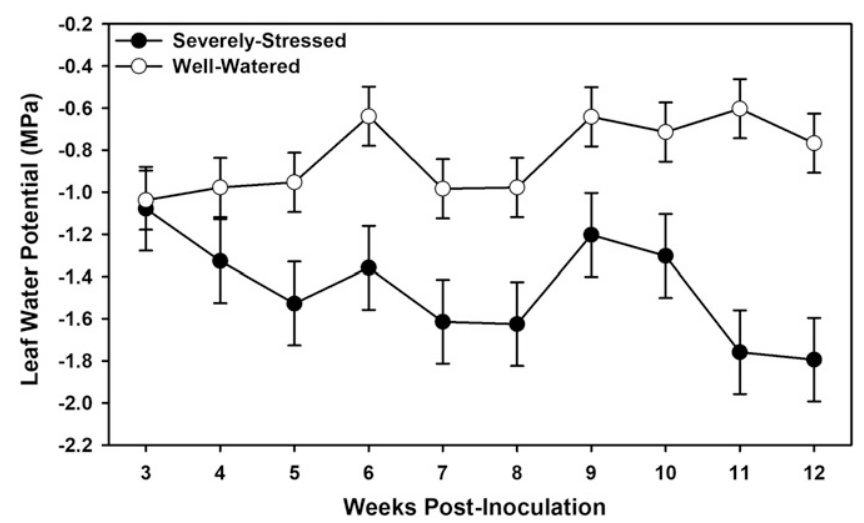

Fig. 1. Leaf water potential (LWP) over 10 weeks for well-watered (WW) plants and water stress induced severely stressed (SS) plants. The SS treatment began at 2 Weeks-Post Inoculation (WPI); the first LWP measurements (in bars, converted to $\mathrm{MPa}$ ) were at $3 \mathrm{WPI}$. Each point is the mean of 18 replicate plants, averaged across inoculation treatments and experiment within each water regime. Bars represent 95\% confidence limits; points within a time point with separated bars are significantly different. higher levels of expression in IW plants. There were only two loci that could be considered as host-based molecular markers of infection at 8 WPI; for VIT_09s0002g06790 and VIT_16s0115g00170 there were greater fold-change differences between IW plants for both water treatments and the NINW-WW control, relative to those of NIW-WW, NIW-SS, and NINW-SS plants (Fig. 2). Increased expression of VIT_09s0002g06790 and VIT_16s0115g00170 in IW plants at 8 WPI was significantly higher than that of NINW-WW (Table 3). Only VIT_16s0115g00170 increased significantly in IW plants only (Table 3). By 12 WPI (10 weeks after water treatments were imposed), expression levels were significantly different among treatments for all eight loci, except VIT_18s0001g00140 (Table 3). At this point in the experiment, no loci could be considered hostbased molecular markers of infection. Instead, there were higher fold changes in SS plants for all loci, regardless of inoculation treatment (Fig. 2), and these differences were significantly higher in all SS treatments as compared with NINW-WW for VIT 05s0020g00330, VIT_09s0002g06790, and VIT_11s0016g03950 (Table 3).

\section{Discussion}

Infection by $N$. parvum was associated with more extensive lesion development in plants under drought stress, compared with that of the well-watered plants. Our finding of larger lesions with the combination of infection and drought stress in 'Cabernet-Sauvignon' is consistent with studies on other wine-grape cultivars 'Chardonnay' and 'Shiraz' under drought conditions (Qiu et al. 2016; van Niekerk et al. 2011). Furthermore, previous studies in grapevine and other woody hosts (e.g., Pinus resinosa) infected by other species in the family Botryosphaeriaceae (e.g., Botryosphaeria dothidea, Diplodia pinea (= Sphaeropsis pinea), Diplodia seriata, Lasiodiplodia theobromae, and Neofusicoccum australe) have shown that when plants

Table 3. Dunnett's test $P$ values (compared with Non-Inoculated NonWounded Well-Watered plants [NINW-WW] as the control, within a time point) for ANOVAs of each putative molecular marker (V1 gene locus ID) that revealed a significant effect of the inoculation $\times$ water treatment interaction on gene expression in the leaves $(P \leq 0.05)$. Vines were in inoculation treatments Inoculated Wounded (IW), Non-Inoculated Wounded (NIW), and Non-Inoculated and Non-Wounded (NINW). After sampling leaves at 2 weeks postinoculation (WPI) for gene expression, water treatments of Well-Watered (WW) and Severely-Stressed (SS) were imposed within the inoculation treatments and then leaves were collected at 8 and 12 WPI. 2 WPI is not shown as there was no significant effect of the inoculation $\times$ water interaction on gene expression $(P \leq 0.05)$.

\begin{tabular}{|c|c|c|c|c|c|}
\hline \multirow[b]{3}{*}{ V1 gene locus ID } & \multicolumn{5}{|c|}{ Dunnett's test $P$ values } \\
\hline & \multicolumn{2}{|c|}{$\begin{array}{c}\text { Well-Watered } \\
\text { (WW) }\end{array}$} & \multicolumn{3}{|c|}{ Severely-Stressed (SS) } \\
\hline & NIW & IW & NINW & NIW & IW \\
\hline \multicolumn{6}{|l|}{$8 \mathrm{WPI}$} \\
\hline VIT_00s1455g00010 & 1.00 & 0.20 & 0.04 & 0.00 & 0.10 \\
\hline VIT_05s0020g00330 & 1.00 & 0.55 & 0.02 & $<0.0001$ & 0.00 \\
\hline VIT_06s0004g06830 & 0.95 & 1.00 & 1.00 & 0.92 & 0.10 \\
\hline VIT_08s0007g04240 & 0.90 & $<0.0001$ & 1.00 & 0.98 & 1.00 \\
\hline VIT_09s0002g06790 & 0.99 & $<0.0001$ & 0.15 & $<0.0001$ & 0.03 \\
\hline VIT_11s0016g03950 & -z & - & - & - & - \\
\hline VIT_16s0115g00170 & 0.56 & 0.00 & 0.25 & 0.50 & 0.01 \\
\hline VIT_18s0001g00140 & 1.00 & 0.18 & 0.07 & 0.01 & 0.18 \\
\hline \multicolumn{6}{|l|}{$12 \mathrm{WPI}$} \\
\hline VIT_00s1455g00010 & 1.00 & 1.00 & 0.00 & 0.75 & 0.18 \\
\hline VIT_05s0020g00330 & 1.00 & 1.00 & $<0.0001$ & $<0.0001$ & $<0.0001$ \\
\hline VIT_06s0004g06830 & 1.00 & 1.00 & 0.00 & 0.77 & 0.02 \\
\hline VIT_08s0007g04240 & 1.00 & 1.00 & 0.00 & 0.75 & 0.00 \\
\hline VIT_09s0002g06790 & 1.00 & 0.99 & $<0.0001$ & $<0.0001$ & $<0.0001$ \\
\hline VIT_11s0016g03950 & 0.95 & 0.99 & $<0.0001$ & 0.00 & $<0.0001$ \\
\hline VIT_16s0115g00170 & 1.00 & 1.00 & 0.00 & 0.44 & 0.01 \\
\hline VIT_18s0001g00140 & - & - & - & - & - \\
\hline
\end{tabular}

${ }^{\mathrm{z}}$ No significant effect of the inoculation $\times$ water interaction on gene expression $(P \leq 0.05)$. 
are subjected to drought stress, lesion development is more severe (Blodgett et al. 1997; Ma et al. 2001; Qiu et al. 2016; van Niekerk et al. 2011). Some studies have shown variability of the influence of drought on Botryosphaeriaceae lesion development, depending on the isolate (Qiu et al. 2016) or the timing of drought stress, either before or after infection (Pusey 1989). In contrast to our findings with $N$. parvum, mean lesion lengths caused by Neofusicoccum luteum were proportional to levels of soil moisture, with plants under low soil moisture ( $25 \%$ field capacity) having the shortest lesions relative to plants under higher soil moistures ( $\geq 50 \%$ field capacity) (Amponsah et al. 2014). After 7 months, E. lata lesion formation was shown to be associated with an interaction of drought and air temperature, such that significantly increased lesion sizes under low soil-water content at $22^{\circ} \mathrm{C}$ were observed, and a trend of decreased lesion sizes under low soil-water content when temperatures were higher $\left(30^{\circ} \mathrm{C}\right)$, but also lower $\left(14^{\circ} \mathrm{C}\right)$ (Sosnowski et al. 2011b). These varying results suggest that lesion development may be influenced by a number of factors, including the aggressiveness of the trunk pathogen and susceptibility of the host cultivar, but also the method of imposing drought stress and when lesions are measured in relation to the period of drought stress.

Lesion development is considered a wood symptom of trunk diseases, in part because it is a visible response by the plant to pathogen colonization. Shigo (1984) described the anatomical and biochemical host-defense responses in the wood of trees infected by fungal pathogens as a process known as 'compartmentalization', containing the reaction zone (i.e., the lesion) that forms in the xylem and attempts to retard further colonization by producing polyphenolic deposits (e.g., gels) and tyloses in vessels, to limit growth of the fungus. N. parvum is known to colonize the xylem of grapevine wood, and infection is associated with lesion formation and induction by the host of vessel occlusions, including tyloses and gels (Czemmel et al. 2015). Interestingly, these same cell-wall thickening and polyphenolic deposits have been associated with drought alone (Fan et al. 2006; Hodaei et al. 2018; Akula and Ravishankar 2011).

Even with the host's attempts to compartmentalize an infection, drought-stressed tissues may be a better substrate for fungal growth. Embolism is prolific in drought-stressed xylem vessels (Brodersen et al. 2013), and such pathways are less saturated, potentially less impeding to hyphae than intact, saturated vessels (Vannini and Valentini 1994). Our finding of $N$. parvum isolated farther from the inoculation site in a greater proportion of IW-SS plants than IWWW plants suggests that fungal colonization rates may increase in conjunction with drought stress. However, other trunk pathogens such as E. lata have not shown a positive correlation with increased colonization distance under drought conditions (Sosnowski et al. 2011b). Regardless, more precise measurements of embolisms and other anatomical responses, localization of the fungal hyphae, and the plant biochemical changes would need to be measured to confirm that less saturated xylem allows for more prolific colonization.

Before drought stress was implemented at 2 WPI, none of the eight host-based markers were significantly up-regulated in IW or NIW leaves, as compared with NINW leaves. After drought was imposed, multiple markers were significantly up-regulated as compared with the NINW-WW controls. Most of the markers were significantly up-regulated in SS plants, regardless of inoculation treatment. During drought, a plant undergoes physiological, biochemical, metabolic, and molecular responses, viewed as wilting foliage and decreased growth, to optimize resources (reviewed in Chaves et al. 2003; Shao et al. 2008; Thapa et al. 2011). The plant closes its stomata to reduce water losses, leading to a reduction in photosynthesis and eliciting multiple, cross-talking pathways (Chaves et al. 2003; Shao et al.
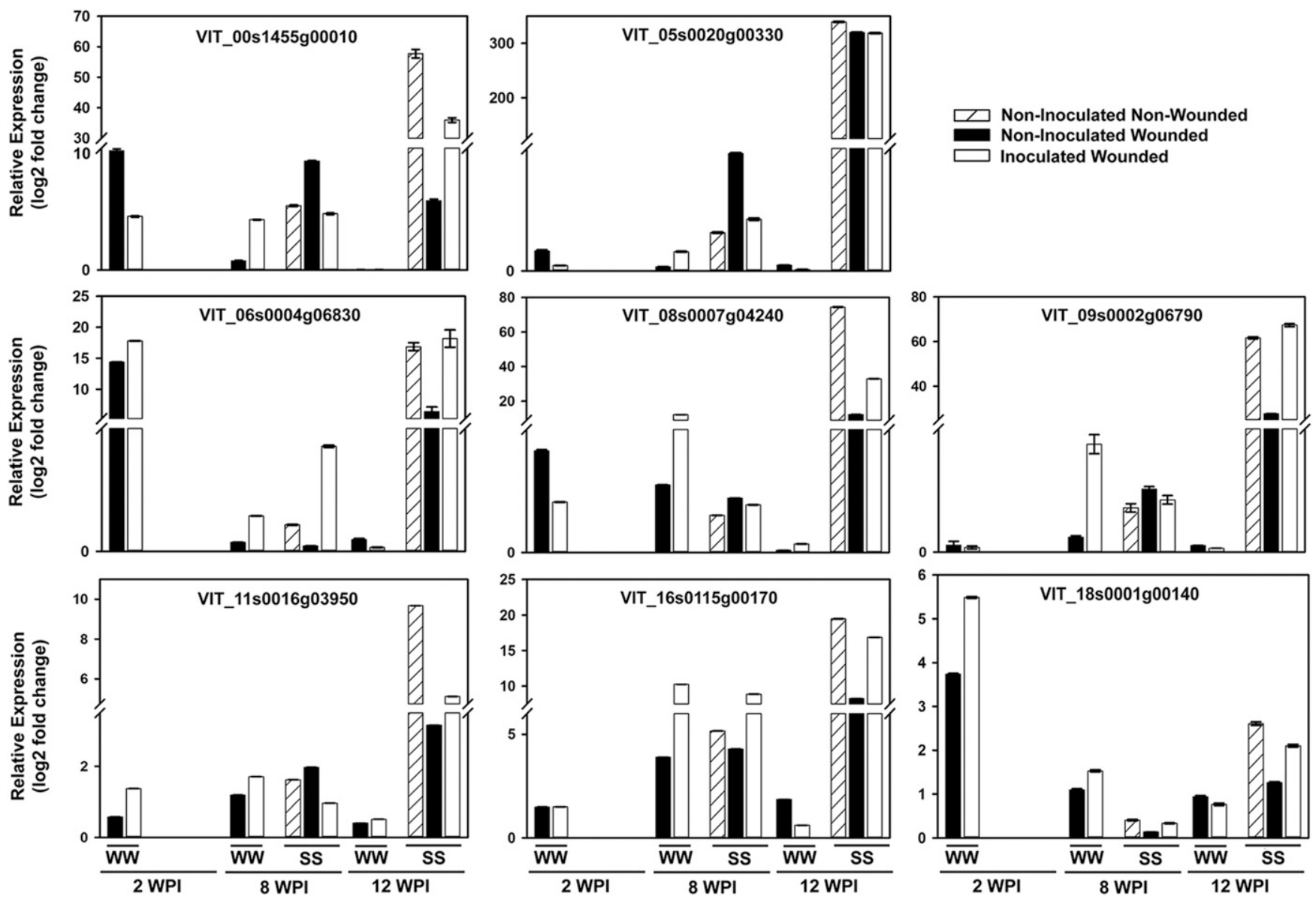

Fig. 2. Fold-change differences in the expression of putative host-based molecular markers of infection in the leaves during Neofusicoccum parvum infection of the woody stem of grapevine, relative to that of Non-Inoculated Non-Wounded Well-Watered (NINW-WW) controls. Transcript levels were corrected to VvUbiquitin1. Each column is the mean of 10 replicate plants, averaged across two experiments. Error bars are standard deviations. 
2008; Singh and Laxmi 2015; Thapa et al. 2011). In this study, wilting and reduced shoot growth was observed among droughtstressed plants. There are hundreds of genes induced throughout the plant under drought conditions (Chaves et al. 2003; Joshi et al. 2016). In addition, a transcriptomic response is detectable in the leaves during $N$. parvum wood infections, but this response is 'muted' and 'delayed' (Massonnet et al. 2017). These processes likely overlap and may have influenced our host-based molecular markers of infection.

The functional annotation for genes examined in this study, some of which were indicative of infection and drought stress at 8 and/or 12 WPI, include associations with drought stress alone in other studies. Up-regulation of VIT_05s0020g00330, VIT_09s0002g06790, and VIT_11s0016g03950 is reported with drought stress in grapevine (Dal Santo et al. 2016; Matus et al. 2014). Orthologs of VIT_ 06s0004g06830, VIT_09s0002g06790, and VIT_11s0016g03950 have been associated with drought in other hosts, including Medicago truncatula, sugarcane, barley, cotton, and Arabidopsis thaliana (Li et al. 2016; Ngamhui et al. 2012; Reddy et al. 2014; Singh et al. 2015; Swindell et al. 2007). At 12 WPI, VIT_05s0020g00330 was up-regulated 300-fold in SS plants, which is consistent with the orthologous proteins' role in functioning as an osmoprotectant (Nishizawa et al. 2008; Taji et al. 2002; Thapa et al. 2011). Upregulation of three other markers, VIT_00s1455g00010, VIT_ 08s0007g04240, and VIT_09s0002g06790, is consistent with that of orthologous genes, which are up-regulated under drought conditions in other plant species (Dal Santo et al. 2013; Joshi et al. 2016).

The most promising marker, VIT_16s0115g00170, which was upregulated at 8 WPI in IW plants regardless of water treatment, was found to be up-regulated in a separate study with application of Abscisic Acid (ABA) to transgenic grapevine cells (Nicolas et al. 2014). Roots can 'signal' to the shoots that there is low soil moisture, through a process that involves increased synthesis of $\mathrm{ABA}$ (Chaves et al. 2003, 2010), an important plant hormone that is transported via xylem sap and induces physiological changes associated with dehydration tolerance (Bostock et al. 2014; Chaves et al. 2003, 2010). Desprez-Loustau et al. (2006) described the interactive effects of drought and disease as having additive deleterious effects on the physiological processes of the plant. Therefore, significant upregulation of VIT_16s0115g00170 early in the experiment only in IW plants, and then later in all SS plants, may reflect such 'additive deleterious effects' of first, infection, and second, the combination of infection and drought stress.

Although the vast majority of California vineyards are irrigated, imposing water stress during a very narrow range of the growing season is a practice known as 'deficit irrigation', and is used by some growers to enhance juice and, thus, wine quality (Chaves et al. 2010; Hochberg et al. 2017; Peterlunger et al. 2005). With recurrent years of drought and the concomitant water shortages in California, vineyards in this Mediterranean-like climate may be under more frequent drought stress at multiple stages of the growing season. Our findings suggest the internal wood symptoms of Botryosphaeria dieback may worsen with drought stress and we might anticipate this could lead to a more rapid decline in vineyard productivity. However, drought stress did not induce an appearance of dieback symptoms during the early stage of infection, still giving us a need for an early detection tool. Our work illustrates the difficulties in developing a molecular-based nondestructive diagnostic tool for asymptomatic, early detection of $N$. parvum infection in the field. Additional research into detection tools during the early stages of infection will need to be completed to achieve this goal. Using host-based molecular markers may be better suited for screening for these chronic infections in nursery stock, which has a brief propagation cycle while vines are grown in a more controlled environment, but additional investigation is necessary to determine the viability of this idea.

\section{Acknowledgments}

We thank A. J. McElrone, United States Department of AgricultureAgricultural Research Service (USDA-ARS; Davis, CA), for guidance with the drought treatments.

\section{Literature Cited}

Akula, R., and Ravishankar, G. A. 2011. Influence of abiotic stress signals on secondary metabolites in plants. Plant Signal. Behav. 6:1720-1731.

Albertazzi, G., Milc, J., Caffagni, A., Francia, E., Roncaglia, E., Ferrari, F., Tagliafico, E., Stefani, E., and Pecchioni, N. 2009. Gene expression in grapevine cultivars in response to Bois Noir phytoplasma infection. Plant Sci. 176:792-804.

Amponsah, N. T., Jones, E. E., Ridgway, H. J., and Jaspers, M. V. 2012 Evaluation of fungicides for the management of Botryosphaeria dieback diseases of grapevines. Pest Manag. Sci. 68:676-683.

Amponsah, N. T., Jones, E. E., Ridgway, H. J., and Jaspers, M. V. 2014. Factors affecting Neofusicoccum luteum infection and disease progression in grapevines. Australas. Plant Pathol. 43:547-556.

Bertsch, C., Ramírez-Suero, M., Magnin-Robert, M., Larignon, P., Chong, J., Abou-Mansour, E., Spagnolo, A., Clément, C., and Fontaine, F. 2013 Grapevine trunk diseases: Complex and still poorly understood. Plant Pathol. 62:243-265.

Blanco-Ulate, B., Vincenti, E., Powell, A. L. T., and Cantu, D. 2013. Tomato transcriptome and mutant analyses suggest a role for plant stress hormones in the interaction between fruit and Botrytis cinerea. Front. Plant Sci. 4:142.

Blodgett, J. T., Kruger, E. L., and Stanosz, G. R. 1997. Effects of moderate water stress on disease development by Sphaeropsis sapinea on red pine. Phytopathology 87:422-428.

Bostock, R. M., Pye, M. F., and Roubtsova, T. V. 2014. Predisposition in plant disease: Exploiting the nexus in abiotic and biotic stress perception and response. Annu. Rev. Phytopathol. 52:517-549.

Brodersen, C. R., McElrone, A. J., Choat, B., Lee, E. F., Shackel, K. A., and Matthews, M. A. 2013. In vivo visualizations of drought-induced embolism spread in Vitis vinifera. Plant Physiol. 161:1820-1829.

Calzarano, F., Di Marco, S., and Cesari, A. 2004. Benefit of fungicide treatment after trunk renewal of vines with different types of esca necrosis. Phytopathol. Mediterr. 43:116-124.

Chaves, M. M., Maroco, J. P., and Pereira, J. S. 2003. Understanding plant responses to drought - From genes to the whole plant. Funct. Plant Biol. 30: 239-264.

Chaves, M. M., Zarrouk, O., Francisco, R., Costa, J. M., Santos, T., Regalado, A. P., Rodrigues, M. L., and Lopes, C. M. 2010. Grapevine under deficit irrigation: Hints from physiological and molecular data. Ann. Bot. 105: 661-676.

Christen, D., Schönmann, S., Jermini, M., Strasser, R. J., and Défago, G. 2007. Characterization and early detection of grapevine (Vitis vinifera) stress responses to esca disease by in situ chlorophyll fluorescence and comparison with drought stress. Environ. Exp. Bot. 60:504-514.

Cramer, G. R., Ergül, A., Grimplet, J., Tillett, R. L., Tattersall, E. A. R., Bohlman, M. C., Vincent, D., Sonderegger, J., Evans, J., Osborne, C., Quilici, D., Schlauch, K. A., Schooley, D. A., and Cushman, J. C. 2007. Water and salinity stress in grapevines: Early and late changes in transcript and metabolite profiles. Funct. Integr. Genomics 7:111-134.

Czemmel, S., Galarneau, E. R., Travadon, R., Mcelrone, A. J., Cramer, G. R., and Baumgartner, K. 2015. Genes expressed in grapevine leaves reveal latent wood infection by the fungal pathogen Neofusicoccum parvum. PLoS One 10: e0121828.

Dal Santo, S., Palliotti, A., Zenoni, S., Tornielli, G. B., Fasoli, M., Paci, P., Tombesi, S., Frioni, T., Silvestroni, O., Bellincontro, A., d'Onofrio, C., Matarese, F., Gatti, M., Poni, S., and Pezzotti, M. 2016. Distinct transcriptome responses to water limitation in isohydric and anisohydric grapevine cultivars. BMC Genomics 17:815

Dal Santo, S., Vannozzi, A., Tornielli, G. B., Fasoli, M., Venturini, L., Pezzotti, M., and Zenoni, S. 2013. Genome-wide analysis of the expansin gene superfamily reveals grapevine-specific structural and functional characteristics. PLoS One 8:e62206.

Desprez-Loustau, M.-L., Marçais, B., Nageleisen, L.-M., Piou, D., and Vannini, A 2006. Interactive effects of drought and pathogens in forest trees. Ann. For. Sci. 63:597-612.

Edwards, J., Salib, S., Thomson, F., and Pascoe, I. G. 2007a. The impact of Phaeomoniella chlamydospora infection on the grapevine's physiological response to water stress Part 1: Zinfandel. Phytopathol. Mediterr. 46:26-37.

Edwards, J., Salib, S., Thomson, F., and Pascoe, I. G. 2007b. The impact of Phaeomoniella chlamydospora infection on the grapevine's physiological response to water stress Part 2: Cabernet Sauvignon and Chardonnay. Phytopathol. Mediterr. 46:38-49.

Evidente, A., Sparapano, L., Andolfi, A., and Bruno, G. 2000. Two naphthalene pentakides from liquid cultures of Phaeoacremonium aleophilum, a fungus associated with Esca of grapevine. Phytopathol. Mediterr. 39:162-168.

Fan, L., Linker, R., Gepstein, S., Tanimoto, E., Yamamoto, R., and Neumann, P. M. 2006. Progressive inhibition by water deficit of cell wall extensibility and growth along the elongation zone of maize roots is related to increased lignin metabolism and progressive stelar accumulation of wall phenolics. Plant Physiol. 140:603-612.

Fleurat-Lessard, P., Luini, E., Berjeaud, J. M., and Roblin, G. 2010. Diagnosis of grapevine esca disease by immunological detection of Phaeomoniella chlamydospora. Aust. J. Grape Wine Res. 16:455-463. 
Fleurat-Lessard, P., Luini, E., Berjeaud, J. M., and Roblin, G. 2014. Immunological detection of Phaeoacremonium aleophilum, a fungal pathogen found in esca disease. Eur. J. Plant Pathol. 139:137-150.

Gramaje, D., Urbez-Torres, J. R., and Sosnowski, M. R. 2018. Managing grapevine trunk diseases with respect to etiology and epidemiology: Current strategies and future prospects. Plant Dis. 102:12-39.

Gupta, A., Sarkar, A. K., and Senthil-Kumar, M. 2016. Global transcriptional analysis reveals unique and shared responses in Arabidopsis thaliana exposed to combined drought and pathogen stress. Front. Plant Sci. 7:686.

Haider, M. S., Kurjogi, M. M., Khalil-Ur-Rehman, M., Fiaz, M., Pervaiz, T., Jiu, S., Haifeng, J., Chen, W., and Fang, J. 2017a. Grapevine immune signaling network in response to drought stress as revealed by transcriptomic analysis. Plant Physiol. Biochem. 121:187-195.

Haider, M. S., Zhang, C., Kurjogi, M. M., Pervaiz, T., Zheng, T., Zhang, C., Lide, C., Shangguan, L., and Fang, J. 2017b. Insights into grapevine defense response against drought as revealed by biochemical, physiological and RNA-Seq analysis. Sci. Rep. 7:13134.

Halleen, F., Fourie, P. H., and Lombard, P. J. 2010. Protection of grapevine pruning wounds against Eutypa lata by biological and chemical methods. S. Afr. J. Enol. Vitic. 31:125-132.

Hillis, V., Lubell, M., Kaplan, J., and Baumgartner, K. 2017. Preventative disease management and grower decision making: A case study of California winegrape growers. Phytopathology 107:704-710.

Hillis, V., Lubell, M., Kaplan, J., Doll, D., and Baumgartner, K. 2016. The role of pest control advisers in preventative management of grapevine trunk diseases. Phytopathology 106:339-347.

Hochberg, U., Degu, A., Rachmilevitch, S., Cramer, G. R., and Fait, A. 2017. Water deficit effects on the molecular processes, physiology and quality of grapevine. Acta Hortic. 239-254.

Hodaei, M., Rahimmalek, M., Arzani, A., and Talebi, M. 2018. The effect of water stress on phytochemical accumulation, bioactive compounds and expression of key genes involved in flavonoid biosynthesis in Chrysanthemum morifolium L. Ind. Crops Prod. 120:295-304.

Joshi, R., Wani, S. H., Singh, B., Bohra, A., Dar, Z. A., Lone, A. A., Pareek, A., and Singla-Pareek, S. L. 2016. Transcription factors and plants response to drought stress: Current understanding and future directions. Front. Plant Sci. 7:1029.

Kaplan, J., Travadon, R., Cooper, M., Hillis, V., Lubell, M., and Baumgartner, K. 2016. Identifying economic hurdles to early adoption of preventative practices: The case of trunk diseases in California winegrape vineyards. Wine Econ. Policy 5:127-141.

Letousey, P., Baillieul, F., Perrot, G., Rabenoelina, F., Boulay, M., VaillantGaveau, N., Clément, C., and Fontaine, F. 2010. Early events prior to visual symptoms in the apoplectic form of grapevine Esca disease. Phytopathology 100:424-431.

Li, S., Bonneu, F., Chadoeuf, J., Picart, D., Gégout-Petit, A., and Guérin-Dubrana, L. 2017. Spatial and temporal pattern analyses of Esca grapevine disease in vineyards in France. Phytopathology 107:59-69.

Li, Y., Chen, X., Chen, Z., Cai, R., Zhang, H., and Xiang, Y. 2016. Identification and expression analysis of BURP domain-containing genes in Medicago truncatula. Front. Plant Sci. 7:485.

Lin, H., Doddapaneni, H., Takahashi, Y., and Walker, M. A. 2007. Comparative analysis of ESTs involved in grape responses to Xylella fastidiosa infection. BMC Plant Biol. 7:8.

Livak, K. J., and Schmittgen, T. D. 2001. Analysis of relative gene expression data using real-time quantitative PCR and the $2^{-\Delta \Delta}$ CT method. Methods 25: 402-408.

Ma, Z., Morgan, D., and Michailides, T. 2001. Effects of water stress on Botryosphaeria blight of pistachio caused by Botryosphaeria dothidea. Plant Dis. 85:745-749.

Mahoney, N., Molyneux, R. J., Smith, L. R., Schoch, T. K., Rolshausen, P. E., and Gubler, W. D. 2005. Dying-Arm disease in grapevines: Diagnosis of infection with Eutypa lata by metabolite analysis. J. Agric. Food Chem. 53:8148-8155.

Massonnet, M., Figueroa-Balderas, R., Galarneau, E. R. A., Miki, S., Lawrence, D. P., Sun, Q., Wallis, C. M., Baumgartner, K., and Cantu, D. 2017. Neofusicoccum parvum colonization of the grapevine woody stem triggers asynchronous host responses at the site of infection and in the leaves. Front. Plant Sci. 8:1117.

Matus, J. T., Aquea, F., Espinoza, C., Vega, A., Cavallini, E., Dal Santo, S., Cañón, P., de la Guardia, A. R., Serrano, J., Tornielli, G. B., and Arce-Johnson, P. 2014. Inspection of the grapevine BURP superfamily highlights an expansion of RD22 genes with distinctive expression features in berry development and ABA-mediated stress responses. PLoS One 9:e110372.

Munkvold, G. P., Duthie, J. A., and Marois, J. J. 1994. Reductions in yield and vegetative growth of grapevines due to Eutypa dieback. Phytopathology 84: 186-192.

Ngamhui, N. O., Akkasaeng, C., Zhu, Y. J., Tantisuwichwong, N., Roytrakul, S., and Sansayawichai, T. 2012. Differentially expressed proteins in sugarcane leaves in response to water deficit stress. Plant Omics 5:365-371.

Nicolas, P., Lecourieux, D., Kappel, C., Cluzet, S., Cramer, G., Delrot, S., and Lecourieux, F. 2014. The basic leucine zipper transcription factor abscisic acid response element-binding factor 2 is an important transcriptional regulator of abscisic acid-dependent grape berry ripening processes. Plant Physiol. 164:365-383.

Nishizawa, A., Yabuta, Y., and Shigeoka, S. 2008. Galactinol and raffinose constitute a novel function to protect plants from oxidative damage. Plant Physiol. 147:1251-1263.

Octave, S., Fleurat-Lessard, P., and Roblin, G. 2009. Diagnosis of Eutypa lata infection in grapevines by serological detection of secreted polypeptides. J. Plant Pathol. 91:321-330.

Peterlunger, E., Sivilotti, P., and Colussi, V. 2005. Water stress increased polyphenolic quality in "Merlot" grapes. Acta Hortic.: 293-300.

Petzoldt, C. H., Moller, W. J., and Sall, M. A. 1981. Eutypa dieback of grapevine: Seasonal differences in infection and duration of susceptibility of pruning wounds. Phytopathology 71:540-543.

Pitt, W. M., Sosnowski, M. R., Huang, R., Qiu, Y., Steel, C. C., and Savocchia, S. 2012. Evaluation of fungicides for the management of Botryosphaeria canker of grapevines. Plant Dis. 96:1303-1308.

Pontin, M. A., Piccoli, P. N., Francisco, R., Bottini, R., Martinez-Zapater, J. M., and Lijavetzky, D. 2010. Transcriptome changes in grapevine (Vitis vinifera L.) cv. Malbec leaves induced by ultraviolet-B radiation. BMC Plant Biol. $10: 224$

Pusey, P. 1989. Influence of water stress on susceptibility of nonwounded peach bark to Botryosphaeria dothidea. Plant Dis. 73:1000-1003.

Qiu, Y., Steel, C. C., Ash, G. J., and Savocchia, S. 2016. Effects of temperature and water stress on the virulence of Botryosphaeriaceae spp. causing dieback of grapevines and their predicted distribution using CLIMEX in Australia. Acta Hortic.: 171-182.

Ramegowda, V., and Senthil-Kumar, M. 2015. The interactive effects of simultaneous biotic and abiotic stresses on plants: Mechanistic understanding from drought and pathogen combination. J. Plant Physiol. 176:47-54

Reddy, P. S., Kavi Kishor, P. B., Seiler, C., Kuhlmann, M., Eschen-Lippold, L., Lee, J., Reddy, M. K., and Sreenivasulu, N. 2014. Unraveling regulation of the small heat shock proteins by the heat shock factor $H v H s f B 2 c$ in barley: Its implications in drought stress response and seed development. PLoS One 9: e89125.

Reis, P., Magnin-Robert, M., Nascimento, T., Spagnolo, A., Abou-Mansour, E., Fioretti, C., Clément, C., Rego, C., and Fontaine, F. 2016. Reproducing Botryosphaeria dieback foliar symptoms in a simple model system. Plant Dis 100:1071-1079.

Rolshausen, P. E., and Gubler, W. D. 2005. Use of boron for the control of Eutypa dieback of grapevines. Plant Dis. 89:734-738.

Rolshausen, P. E., Úrbez-Torres, J. R., Rooney-Latham, S., Eskalen, A., Smith, R J., and Gubler, W. D. 2010. Evaluation of pruning wound susceptibility and protection against fungi associated with grapevine trunk diseases. Am. J. Enol. Vitic. 61:113-119.

Shao, H. B., Chu, L. Y., Jaleel, C. A., and Zhao, C. X. 2008. Water-deficit stressinduced anatomical changes in higher plants. C. R. Biol. 331:215-225.

Shigo, A. L. 1984. Compartmentalization: A conceptual framework for understanding how trees grow and defend themselves. Annu. Rev. Phytopathol. 22:189-214.

Singh, D., and Laxmi, A. 2015. Transcriptional regulation of drought response A tortuous network of transcriptional factors. Front. Plant Sci. 6:895.

Singh, R., Pandey, N., Naskar, J., and Shirke, P. A. 2015. Physiological performance and differential expression profiling of genes associated with drought tolerance in contrasting varieties of two Gossypium species. Protoplasma 252:423-438.

Sinha, R., Gupta, A., and Senthil-Kumar, M. 2017. Concurrent drought stress and vascular pathogen infection induce common and distinct transcriptomic responses in chickpea. Front. Plant Sci. 8:333.

Sipiora, M. J., and Cuellar, S. 2014. Economic impact of Eutypa dieback. Wine Bus. Mon. Oct:46-49.

Smith, R., and Prichard, T. 2003. Using a pressure chamber in winegrapes. UC Coop. Ext., University of California, Davis.

Sosnowski, M. R., Loschiavo, A. P., Wicks, T. J., and Scott, E. S. 2013. Evaluating treatments and spray application for protection of grapevine pruning wounds from infection by Eutypa lata. Plant Dis. 97:1599-1604.

Sosnowski, M. R., Luque, J., Loschiavo, A. P., Martos, S., Garcia-Figueres, F., Wicks, T. J., and Scott, E. S. 2011b. Studies on the effect of water and temperature stress on grapevine inoculated with Eutypa lata. Phytopathol. Mediterr. 50:127-139

Sosnowski, M. R., Wicks, T. J., and Scott, E. S. 2011a. Control of Eutypa dieback in grapevines using remedial surgery. Phytopathol. Mediterr. 50:277-284.

Sun, Q., Sun, Y., Walker, M. A., and Labavitch, J. M. 2013. Vascular occlusions in grapevines with Pierce's Disease make disease symptom development worse. Plant Physiol. 161:1529-1541.

Swindell, W. R., Huebner, M., and Weber, A. P. 2007. Transcriptional profiling of Arabidopsis heat shock proteins and transcription factors reveals extensive overlap between heat and non-heat stress response pathways. BMC Genomics 8:125

Tabacchi, R., Fkyerat, A., Poliart, C., and Dubin, G. M. 2000. Phytotoxins from fungi of Esca of grapevine. Phytopathol. Mediterr. 39:156-161.

Taji, T., Ohsumi, C., Iuchi, S., Seki, M., Kasuga, M., Kobayashi, M., YamaguchiShinozaki, K., and Shinozaki, K. 2002. Important roles of drought- and 
cold-inducible genes for galactinol synthase in stress tolerance in Arabidopsis thaliana. Plant J. 29:417-426.

Thapa, G., Dey, M., Sahoo, L., and Panda, S. K. 2011. An insight into the drought stress induced alterations in plants. Biol. Plant. 55:603-613.

Trapero, C., Alcántara, E., Jiménez, J., Amaro-Ventura, M. C., Romero, J., Koopmann, B., Karlovsky, P., von Tiedemann, A., Pérez-Rodriguez, M., and López-Escudero, F. J. 2018. Starch hydrolysis and vessel occlusion related to wilt symptoms in olive stems of susceptible cultivars infected by Verticillium dahliae. Front. Plant Sci. 9:72.

Travadon, R., Lecomte, P., Diarra, B., Lawrence, D. P., Renault, D., Ojeda, H., Rey, P., and Baumgartner, K. 2016. Grapevine pruning systems and cultivars influence the diversity of wood-colonizing fungi. Fungal Ecol. 24:82-93.

Travadon, R., Rolshausen, P. E., Gubler, W. D., Cadle-Davidson, L., and Baumgartner, K. 2013. Susceptibility of cultivated and wild Vitis spp. to wood infection by fungal trunk pathogens. Plant Dis. 97:1529-1536.

van Niekerk, J. M., Strever, A. E., du Toit, P. G., Halleen, F., and Fourie, P. H. 2011. Influence of water stress on Botryosphaeriaceae disease expression in grapevines. Phytopathol. Mediterr. 50:151-165.
Vannini, A., and Valentini, R. 1994. Influence of water relations on Quercus cerris-Hypoxylon mediterraneum interaction: A model of drought-induced susceptibility to a weakness parasite. Tree Physiol. 14:129-139.

Vannozzi, A., Donnini, S., Vigani, G., Corso, M., Valle, G., Vitulo, N., Bonghi, C., Zocchi, G., and Lucchin, M. 2017. Transcriptional characterization of a widelyused grapevine rootstock genotype under different Iron-limited conditions. Front. Plant Sci. 7:1994.

Weber, E. A., Trouillas, F. P., and Gubler, W. D. 2007. Double pruning of grapevines: A cultural practice to reduce infections by Eutypa lata. Am. J. Enol. Vitic. 58:61-66.

Xin, H., Zhu, W., Wang, L., Xiang, Y., Fang, L., Li, J., Sun, X., Wang, N., Londo, J. P., and Li, S. 2013. Genome wide transcriptional profile analysis of Vitis amurensis and Vitis vinifera in response to cold stress. PLoS One 8:e58740.

Yadet, K. A., and Thomma, B. P. H. J. 2013. The xylem as battleground for plant hosts and vascular wilt pathogens. Front. Plant Sci. 4:97.

Ye, J., Coulouris, G., Zaretskaya, I., Cutcutache, I., Rozen, S., and Madden, T. L. 2012. Primer-BLAST: A tool to design target-specific primers for polymerase chain reaction. BMC Bioinformatics 13:134. 